\title{
The Differential Effects of Intimate Terrorism and Situational Couple Violence

\author{
Findings From the National
} \\ Violence Against Women Survey
}

\author{
MICHAEL P. JOHNSON \\ JANEL M. LEONE \\ Pennsylvania State University
}

\begin{abstract}
Data from the National Violence Against Women Survey show that the two major forms of husband violence toward their wives (intimate terrorism and situational couple violence) have different effects on their victims. Victims of intimate terrorism are attacked more frequently and experience violence that is less likely to stop. They are more likely to be injured, to exhibit more of the symptoms of posttraumatic stress syndrome, to use painkillers (perhaps also tranquilizers), and to miss work. They have left their husbands more often, and when they do leave, they are more likely to acquire their own residence. If we want to understand the true impact of wife abuse from survey data (rather than from agency data), we must make distinctions among types of violence so that the data used to describe battering are not diluted by data regarding other types of partner violence.
\end{abstract}

Keywords: domestic violence; battering; control; marriage; gender

M.P. Johnson (1995) has argued that there are two distinct forms of male violence against female partners. The basic pattern in what he called patriarchal terrorism (which we will refer to as intimate terrorism, as he does in more recent articles) is violence that is embedded in a general pattern of controlling behaviors, indicating that the perpetrator is attempting to exert general control over his partner. Johnson suggests that this form of violence is what is typically intended by terms such as domestic violence, wife beating, and spousal abuse. In contrast, the intimate partner violence that he called common couple violence (which we will refer to as situational couple violence, as he does in more recent articles) is violence that

Authors' Note: This is a revised version of a paper presented at the Tenth International Conference on Personal Relationships, Brisbane, Australia, July 2000.

JOURNAL OF FAMILY ISSUES, Vol. 26 No. 3, April 2005 322-349

DOI: $10.1177 / 0192513$ X04270345

(c) 2005 Sage Publications

322 
is not connected to a general pattern of control. He describes this violence as involving specific arguments that escalate to violence but showing no relationship-wide evidence of an attempt to exert general control over one's partner. M. P. Johnson (1995) and Johnson and Ferraro (2000) have made the case that these distinctions are central because they have implications for the development of theories of interpersonal violence, the design of educational programs and intervention strategies, and the implementation of public policy. We believe that these distinctions between different forms of partner violence are also important for understanding the effects of violence on its victims.

\section{P. JOHNSON'S CONTROL TYPOLOGY OF INTIMATE PARTNER VIOLENCE}

The theoretical foundations of Johnson's control typology are grounded in the ostensibly mutually contradictory analyses of feminist theory and family violence theory. Feminist theory (Dobash \& Dobash, 1979; Stark \& Flitcraft, 1996; Stets, 1988; Yllo \& Bograd, 1988) conceptualizes intimate partner violence as a matter of control, rooted in patriarchal traditions of male dominance in heterosexual relationships, especially marriage. Family violence theory sees intimate partner violence as a matter of conflict, rooted in the everyday stresses of family life that produce conflicts that may or may not escalate to violence (Straus, Gelles, \& Steinmetz, 1980; Straus \& Smith, 1990). Johnson asserts that although these theories have generally been framed as alternative understandings of the same phenomenon, they are better understood as explanations of two essentially different forms of intimate partner violence: one rooted in an attempt to exert general control over the relationship (intimate terrorism) and the other arising out of particular conflicts (situational couple violence).

Intimate terrorism is defined by the attempt to dominate one's partner and to exert general control over the relationship, domination that is manifested in the use of a wide range of power and control tactics, including violence. Although many authors working in the feminist tradition have described this general pattern of controlling behavior (Campbell, Rose, Kub, \& Nedd, 1998; Dobash \& Dobash, 1979; Ferraro, 1997; M. P. Johnson, 1995; Kirkwood, 1993; Lloyd \& Emery, 2000; Stark \& Flitcraft, 1996; Yllo \& Bograd, 1988), the best known description is probably that embodied in Pence and Paymar's (1993, p. 185) Power and Control Wheel, which includes the following nonviolent control tactics: emotional abuse, isolation, using children, using male privilege, economic 
abuse, threats, intimidation, and blaming. The core idea of these theories of coercive control is that even the nonviolent control tactics take on a violent meaning that they would not have in the absence of their connection with violence. Imagine, for example, the different meaning and emotional impact of an intimidating look from a nonviolent partner and a similar gesture from a partner who has already demonstrated his willingness to be violent. As the victims of intimate terrorism often report, "all he had to do was look at me that way and I would do whatever he wanted" (Dobash \& Dobash, 1979).

Situational couple violence is defined as intimate partner violence that is not embedded in such a general pattern of controlling behaviors. Its particular causes may vary from couple to couple and across different incidents of violence experienced by the same couple, but there is no relationship-wide pattern of controlling behaviors. This form of intimate partner violence is not rooted in a general pattern of control but occurs when specific conflict situations escalate to violence. It is probably best understood through the conceptual framework of family conflict theory (Bradbury, Rogge, \& Lawrence, 2001; Gelles \& Straus, 1988; Steinmetz, 1986; Straus \& Gelles, 1990; Straus et al., 1980), in which it assumed that conflict is endemic to family life; that in the American cultural context, some kinds of family violence are considered acceptable under some conditions; and that, therefore, family conflicts will sometimes lead to violence. Johnson argued that this understanding of family violence does indeed describe most of the intimate partner violence that is uncovered in general surveys.

The violent acts involved in both situational couple violence and intimate terrorism can range from relatively innocuous behavior, such as pushing and shoving, to life-threatening attacks or homicide, and both types of violent relationships can involve anything from infrequent, isolated incidents to regular assaults. In the case of frequent situational couple violence, for example, the relationship may involve areas of conflict that continue to be unresolved and one or more partners who regularly choose to resort to violence in the context of those conflicts. In the case of infrequent intimate terrorism, one assault may be enough to establish a level of fear that allows the intimate terrorist to exert control almost exclusively by means of nonviolent tactics. Thus, the two types of violence are not defined by the nature or frequency of violent acts but solely in terms of the relationship-level control context in which they are embedded. Intimate terrorism is violence that is embedded in a general pattern of control; situational couple violence is not. 
Why create a typology rather than using control as a continuous variable? The core theoretical idea that informs M. P. Johnson's typology is that intimate terrorism is driven by an attempt to exert general control over one's partner, whereas situational couple violence is a much less coherent phenomenon. Although there may be considerable variability in the level of control exhibited in intimate partner relationships, among violent couples, there is a qualitative distinction between these two types. Johnson argues that because these types of violence have different psychological and social roots, interpersonal dynamics, and consequences for the victim, much of the empirical domestic violence literature is virtually meaningless. Without operationalization of the distinctions, the observed statistical relationships (whether strong, weak, or nonexistent) are a function of unknown mixes of the different types of violence. For example, studies that do not make these distinctions have generally found that there is more violence in cohabiting relationships than in marriages, a finding that has puzzled theorists who see the "marriage license as a hitting license" (Stets \& Straus, 1989). Johnson's typological approach suggests that the patriarchal traditions of marriage should affect primarily intimate terrorism, in which control is a major factor, whereas the inevitable conflicts of family life that are the source of situational couple violence are as likely to be a feature of cohabitation as they are of marriage. In fact, when Macmillan and Gartner (1999) recently distinguished between situational couple violence and intimate terrorism in their analysis of the Canadian Violence Against Women Survey, they found that intimate terrorism was indeed more prevalent among married couples. It was only situational couple violence that was more likely in cohabiting relationships (Table 3, p. 954). In a similar example of the clarity to be gained by distinguishing between types of violence, Johnson has shown that the longstanding debate regarding the gender symmetry of domestic violence can be resolved by making his distinctions. Reanalyzing data from Frieze's Pittsburgh study (Frieze $\&$ Browne, 1989), he has shown that situational couple violence in heterosexual relationships is roughly gender symmetric, whereas intimate terrorism is perpetrated almost entirely by men (M. P. Johnson, 2001). Both of these examples relate to the causes of intimate terrorism and situational couple violence and lend support to the theoretical argument that intimate terrorism has its primary roots in male domination of women, as feminist theorists have long contended. Our goal in this article, however, is to investigate the other end of this theory of intimate partner violence by asking whether the different types of violence have different effects on the victims. 


\section{THE EFFECTS OF INTIMATE PARTNER VIOLENCE}

Researchers have found that domestic violence has many negative consequences for its victims. In addition to the injuries that are the immediate consequence of violence, there are other physical and psychological health risks (Giles-Sims, 1998; Holtzworth-Munroe, Smutzler, \& Sandin, 1997). The psychological effects include posttraumatic stress disorder, depression, and lowered self-esteem (Kirkwood, 1993). The economic effect of domestic violence is another area of focus. Browne, Salomon, and Bassuk (1999) report that women who experienced violence from male partners during a 12-month period "had about one third the odds of working at least 30 hours per week for 6 months or more during the following year as did women who had not experienced such aggression" (p. 417). Other examinations of the effects of battering on women's employment have reported that abusive men deliberately undermine women's employment by depriving them of transportation, harassing them at work, turning off alarm clocks, beating them before job interviews, and disappearing when they promised to provide child care (Brandwein, 1998; Lloyd, 1997).

Unfortunately, the research that has demonstrated these negative effects has not distinguished among types of domestic violence. The general hypothesis of this study is that the negative effects of domestic violence are more severe for intimate terrorism than they are for situational couple violence. This is not to say that situational couple violence has no negative effects on its victims, only that they are on average less severe than the effects of intimate terrorism.

The data that we use allow us to test this general hypothesis in five areas. First, we expect the pattern of the violence itself to differ, the violence of intimate terrorism being (on average) more frequent and more severe. We remind the reader that the two types of violence are not defined in terms of frequency or severity of violent acts but rather in terms of control context. We hypothesize that the intention to exert general control makes intimate terrorism more likely than situational couple violence to involve severe or frequent violence. This is a matter of theory, not definition. Some intimate terrorists may gain control without resorting to a high level of violence. Similarly, situational couple violence, although more likely than intimate terrorism to involve only isolated low-level violence, can in some cases be frequent or deadly. Second, we expect that immediate injuries and other negative medical outcomes will be more likely for intimate terrorism than they are in the case of situational couple violence. The greater likelihood of immediate injuries would follow from the correla- 
tion of intimate terrorism with frequency and severity of violence. There are, however, also likely to be physical health consequences that are caused by the long-term stress of being trapped in a controlling, threatening relationship. Third, the general pattern of control and the implicit threat of violence involved in intimate terrorism will be more likely to undermine the victims' psychological health than will the less systematic threat of situational couple violence. Fourth, the systematic control involved in intimate terrorism will be more likely to interfere with the daily activities of life, including employment. Finally, the generally negative effects of intimate terrorism should lead its victims to be less satisfied with the relationship, more likely to attempt to escape, and more likely to seek help.

\section{METHOD}

\section{SAMPLE}

The data used in the current study are from the National Violence Against Women Survey (NVAWS), a cross-sectional national randomsample telephone interview intended to examine several types of violence against women, including rape, physical assault, emotional abuse, and stalking (Tjaden \& Thoennes, 1999). Data were collected from a national, random-digit sample of telephone households in the United States; 8,005 men and 8,000 women 18 years of age or older were interviewed. Because much of the published work dealing with partner violence focuses on married respondents and because other studies have shown differences in the nature of partner violence as a function of marital status, we chose to limit our analyses to the 4,967 women who were married at the time of the interview. The data we use refer to their current husbands.

Respondents in our subsample ranged in age from 18 to $97(M=44.55$, $S D=13.89$ ). At the time of the survey, $46 \%$ of the respondents reported working full-time, $15 \%$ were employed part-time, $21 \%$ were homemakers, and $12 \%$ were retired. The other $10 \%$ were either in the military, students, or doing something else. Furthermore, $87 \%$ of the respondents reported themselves as White, 5\% as African American, 2\% as Asian, 5\% as mixed race, and $1 \%$ as American Indian or Alaskan Native. Nine percent of the respondents had not graduated from high school, $36 \%$ had earned a high school degree, $28 \%$ had some college education, $18 \%$ had earned a college degree, and $9 \%$ had completed postgraduate work. 


\section{PROCEDURE}

The NVAWS was conducted by a national research organization based in New York City. Prospective participants were first given an extensive pretest to determine eligibility. Interviews were acquired by means of a computer-assisted interviewing system. The version of the survey completed by women was administered in 1995 and 1996. Because of the sensitive content included in the survey, females interviewed female respondents, and Spanish-speaking respondents were interviewed in Spanish by bilingual interviewers.

Participation rates were calculated using the following formula: the number of completed interviews, including those that were screened out as ineligible, divided by the total number of completed interviews, refusals, and terminated interviews. Using this formula, the participation rate among women was $72 \%$. Of the eligible women who started the interview, $97 \%$ completed the survey.

\section{MEASURE}

Physical violence. Physical violence was operationalized as both a continuous variable and a dichotomous variable, based on responses to a 12-item, yes-no version of the physical violence items of the Conflict Tactics Scales (Straus, 1990a, 1990b). The continuous variable, the Violence Scale, is the number of the 12 violent behaviors ever perpetrated in the relationship by each respondent's husband. Cronbach's alpha is .88 . The overall mean of the scale for the reported behavior of all husbands is .87 $(S D=1.98)$, with scores ranging from 0 to 12 . The dichotomous violence variable was created such that respondents who experienced none of the 12 violent acts $(n=4,721)$ were coded nonviolent. Respondents who experienced one or more of the 12 violent acts $(n=246)$ were coded violent.

We also created a Severe Violence Scale based on the items conventionally identified as severe violence. These items were choke or attempt to drown, hit you with an object, beat you up, threaten you with a gun, threaten you with a knife or other weapon besides a gun, use a gun on you, and use a knife or other weapon. The Severe Violence Scale score is simply the number of those seven items for which the respondent replied yes regarding her husband's behavior. Cronbach's alpha for the scale is .78. Scores covered the full range from 0 to 7 , with an overall mean among all husbands of .30 . 
Nonviolent control. The NVAWS included seven items assessing nonviolent control tactics used by the respondent's husband. Many of these items were adopted from the Canadian Violence Against Women Survey (H. Johnson, 1996) and closely resemble items included in the Psychological Maltreatment of Women Survey (Tolman, 1989). They include the following: Thinking about your current husband, would you say he ... tries to limit your contact with family and friends? ... is jealous or possessive? ... insists on knowing who you are with at all times? . . . calls you names or puts you down in front of others? ... makes you feel inadequate? ... shouts or swears at you? ... prevents you from knowing about or having access to the family income even when you ask? Response options to each of the items were no (0) or yes (1).

A principal components analysis was conducted to determine if the items represented more than one construct. The pattern of eigenvalues $(2.52,1.06, .88, .71, .66, .59$, and .58$)$ with a strong first factor suggested to us that a reasonable seven-item scale could be constructed from these items. The Control Scale score is the number of control tactics the respondent's husband was reported to have used, with a potential range of 0 to 7 . The overall mean of the scale for all husbands is .39 $(S D=.94)$, the median is 0 , and actual scores cover the entire range from 0 to 7 . Cronbach's alpha is .70 .

To operationalize the distinction between intimate terrorism and situational couple violence, we needed to choose a cutting point to distinguish between high and low control. To avoid choosing a totally arbitrary cutting point for the distinction between high and low patterns of control, we used a cluster analysis of the seven individual items in the Control Scale to guide us. A $k$-means cluster analysis with a two-cluster solution was performed on the seven variables to identify natural clusters of controlling behavior for the violent husbands. We then chose our cutting point for the dichotomization to maximize the fit between the cluster solution and the dichotomized Control Scale. (Details are available from the authors.) Husbands using three or more of the seven control tactics were coded high control ( $n=211)$, those using two or fewer as low control $(n=4,575)$. For researchers who may be using other measures of control, we point out that this cutting point corresponds to two standard deviations above the mean of the Control Scale for the reported behavior of all husbands in the NVAWS.

Violence type. Intimate terrorism is defined as physical violence embedded in a general pattern of control, and situational couple violence is 
physical violence that is not embedded in a general pattern of control. Using the dichotomization of the Control Scale discussed above, the behavior of violent husbands who were reported to have used three or more of the seven control tactics was coded as intimate terrorism $(n=81)$. If a violent husband was reported to have used two or fewer of the seven control tactics, his behavior was coded as situational couple violence $(n=149)$.

One issue raised for us by the outcome of this coding process was the surprisingly high representation of intimate terrorism among the violent men in this sample. M. P. Johnson (1995) has argued that there should be almost no intimate terrorism in general survey samples, and he demonstrated for one such survey that only $10 \%$ of the male violence was intimate terrorism (Johnson, 2001). Why does 35\% of husbands' violence in the NVAWS consist of intimate terrorism? We believe that the answer lies in the general framing of the NVAWS interview. We agree with Straus's (1999) argument that the more an interview is framed in terms of violence or crime in the minds of the respondents (rather than as conflict, as it is framed in his National Survey of Family Violence), the less violence would be reported, but the more severe that violence would be. As Straus points out, the NVAWS is not framed for the respondent as a study of family life or even of family conflict but is presented as a study of personal safety, injury, and violence, with a decided crime overtone. We would argue (analogously to Straus) that in such a frame of mind, a respondent who experienced violence in a general context of control would be more likely to report that violence than would a respondent who experienced more isolated violence.

Injuries sustained from violence. Unfortunately, the only injury data collected in the NVAWS concerns injuries sustained in the most recent incident of partner violence: Were you physically injured during this [most recent] incident? Of the respondents whose husbands had been violent, $78 \%$ had not been injured in the most recent incident $(n=192)$, and $22 \%$ had been injured $(n=54)$.

Psychological well-being. A 21-item scale adapted from the Impact of Event Scale (Weiss \& Marmar, 1997) was used in the NVAWS to assess respondents' symptoms of post-traumatic stress disorder (PTSD) resulting from their husband's violence. Respondents who had experienced violence were instructed to think about the physical violence and respond to a list of difficulties people commonly face following such stressful events. Respondents were instructed to report how much each of the difficulties had bothered them in the previous 7 days. Some of the statements included 
"I had trouble falling asleep," "I felt irritable and angry," "I felt it didn't happen or wasn't real," "I was jumpy and easily startled," "my feelings about it were kind of numb," and "reminders of it caused me to have physical reactions, such as sweating, trouble breathing, nausea, or heart pounding." Response options were not at all (1), a little bit (2), moderately (3), and quite a bit (4). The PTSD Symptom Scale score was the mean of all items answered for respondents who answered at least 19 of the 21 items. The overall mean was $1.47(S D=.67)$, the median was 1.14 , and the scores ranged from 1.00 to 3.76. Cronbach's alpha was .95 .

An eight-item Depression Symptoms Scale, based on questions used in the SF-36 Health Survey, U.S. Acute Version, 1.0, was used to assess level of depression of all respondents. The time referent for all items was the past week, and the items were as follows: How often in the past week ... did you feel full of pep? ... did you have a lot of energy? ... have you been a happy person? ... did you feel tired? ... have you been very nervous? ... have you felt so down in the dumps that nothing could cheer you up? ... did you feel downhearted and blue? ... did you feel worn out? Three of the eight questions were reverse coded for scoring purposes. Response options were never (1), rarely (2), some of the time (3), and most of the time (4). The mean was calculated for each respondent who answered all of the items. The mean score was $1.93(S D=.51)$, and the scores ranged from 1.00 to 4.00 . Cronbach's alpha was .78 .

Drug use. Drug use in the month prior to the interview was assessed for all respondents, regardless of whether they experienced partner violence. We examined the relationship between type of violence and three specific drug categories: (a) tranquilizers, sleeping pills, or sedatives; (b) antidepressants; and (c) pain killers. Respondents answered yes or no to using each type.

Interference of violence with everyday activities. Once again, we were handicapped by the fact that lost-work-time questions were asked only with respect to the effects of the most recent violent incident. Effects on the respondent's labor force participation were assessed by responses to the following yes-or-no question: Did you ever have to take time off from work for which you were getting paid [because of this incident]?

Leaving and seeking help. Respondents whose husbands had been violent were asked the following: Did you ever leave your current husband because he was violent toward you? If the respondent answered affirmatively, she was asked the following: How many different times did you 
leave? Answers to this question ranged from 1 to 78 . We combined these two questions to create a continuous variable of the number of times left that ranged from 0 (never left) to 78 . The third question, referring to only the most recent time the respondent left her husband, asked the following: Where did you stay? Respondents chose from a list of the following possible places: relative's house, with a friend, got her own place, safe house, hotel, homeless shelter, he left and she stayed, or other.

Demographic characteristics. Respondent demographic characteristics included age ( 18 to 97 years old), education level ( $1=$ no schooling to 7 = postgraduate $), 1995$ household income before taxes $(1=$ less than $\$ 5,000$ to $10=$ greater than $\$ 100,000$ ), and race (White, Black, Other).

\section{RESULTS AND DISCUSSION}

In most cases, the questions we analyzed were asked only of respondents who had reported violence from their husbands. Whenever a question was also asked of other respondents, we presented data comparing the responses of women experiencing each type of violence with the responses of women who had never experienced violence from their husbands.

Hypothesis 1: Intimate terrorism involves more frequent and severe physical violence, and the violence is less likely to stop.

First, NVAWS respondents who reported that their husband had been violent toward them were asked the following: How many different times has he done this to you [been physically violent]? The means for respondents who reported any physical violence were $8.13(S D=17.50)$ for intimate terrorism and $2.63(S D=2.88)$ for situational couple violence $(F=$ $12.99, d f=1,204, p<.001)$. These results indicate that women subjected to intimate terrorism experienced more frequent violence compared to women who experienced situational couple violence, thereby confirming the first part of Hypothesis 1.

Second, we examined the relationship between violence type and Severe Violence Scale score, which is the number of different severely violent behaviors husbands were reported to have employed. Out of a possible score of 7, the mean score for victims of intimate terrorism was 1.07 $(S D=1.55)$, compared to $.53(S D=1.02)$ for situational couple violence $(F=10.21, d f=1,228, p<.01)$. On average, victims of intimate terrorism experienced significantly more severe violence than victims of situational 
couple violence. These findings empirically support the second component of Hypothesis 1.

Because some reviewers have suggested that the findings regarding frequency and severity are tautological, we feel it is important to remind the reader that the types of violence are not defined in terms of frequency or severity or any other characteristic of the acts of physical violence themselves but rather in terms of the extent to which the violent husband uses a variety of other, nonviolent, control tactics. Although there are average differences between the two types of violence in terms of the frequency and severity of violence, in some cases, even situational couple violence can be quite frequent or extremely severe. Similarly, it is not always the case that intimate terrorism involves frequent or severe violence. For example, in these data, there is one case of situational couple violence in which the husband had been violent 20 times, and there are 19 cases of intimate terrorism in which the husbands had been violent only once. With respect to severity, $52 \%$ of the perpetrators of intimate terrorism had never committed an act of severe violence. Thirty-two percent of the perpetrators of situational couple violence had committed at least one act of severe violence, and there is even one case of situational couple violence in which the perpetrator had used all seven forms of severe violence. The finding that intimate terrorism is more likely than situational couple violence to be frequent and severe is hardly tautological.

Finally, intimate terrorism has also been shown to be less likely to stop (M. P. Johnson, 1999). Although there was no direct question in the NVAWS regarding desistance, we could at least look at differences between the two types of violence in terms of date of the most recent incident. A report of no violence in the past 12 months provides a reasonable indicator of desistance. Results indicated that $99 \%$ of the situational couple violence group had experienced no violence in the past 12 months, as compared with $78 \%$ of the intimate terrorism group $\left(\chi^{2}=16.23, d f=1, p<\right.$ .001 ), supporting the third part of Hypothesis 1 .

Hypothesis 2: Intimate terrorism does more damage to the physical health of its victims than situational couple violence does.

The NVAWS data allow only a very conservative test of this hypothesis, as injury data were collected regarding only the most recent incident, which in most cases will not be the most severe level of injury ever experienced. No questions were asked regarding injuries either throughout the history of the violent relationship or for the most severe incident. Nevertheless, the data do provide support for Hypothesis 2. Logistic regression 
analyses (Table 1) indicate that type of violence is significantly related to injury both at the zero order (Model 1) and after controlling for a few background characteristics of respondents (Model 2). Although the coefficient for violence type is reduced somewhat by the control for Violence Scale Score (Model 3), the odds of being injured were still two and a half times higher for women experiencing intimate terrorism than for those experiencing situational couple violence. A test for the interaction between violence type and Violence Scale Score was not significant $(\exp (B)=.78$, $p=.16$ ).

It is clear from these analyses that intimate terrorism is more likely to produce injuries than situational couple violence is, but we believe that the relationship is mediated much more by level of violence than these data suggest. Remember that the Violence Scale refers to all violence in the relationship, whereas the injury data refer only to the most recent incident. Although intimate terrorism does not always involve frequent or severe violence, the use of violence to exert general control will, on average, produce more frequent and more severe acts of violence that will in turn increase the likelihood of injury.

Hypothesis 3: Intimate terrorism does more damage to the psychological health of its victims than situational couple violence does.

To explore the relationship between type of violence and respondents' scores on the PTSD Symptom Scale, we conducted a hierarchical Ordinary Least Squares (OLS) regression (see Table 2). Results indicated that experiencing intimate terrorism and increased scores on the Violence Scale were both significantly related to higher scores on the PTSD Symptom Scale (see Model 3). Model 4 shows a significant interaction between these two factors, indicating that victims of intimate terrorism reported significantly more PTSD symptoms as level of violence increased, whereas this was not the case for victims of situational couple violence (see Figure 1).

In addition to PTSD symptoms, we examined the relationship between type of violence respondents experienced and their scores on the Depression Symptoms Scale. Results of a hierarchical OLS regression revealed that victims of both intimate terrorism and situational couple violence scored significantly higher on the Depression Symptoms Scale than did women who did not experience violence (see Table 3). The difference in depression symptoms between types of violence was not statistically significant $(t=.96, p=.34)$. Results also indicated that scores on the Violence Scale were significantly related to scores on the Depression Symptoms 


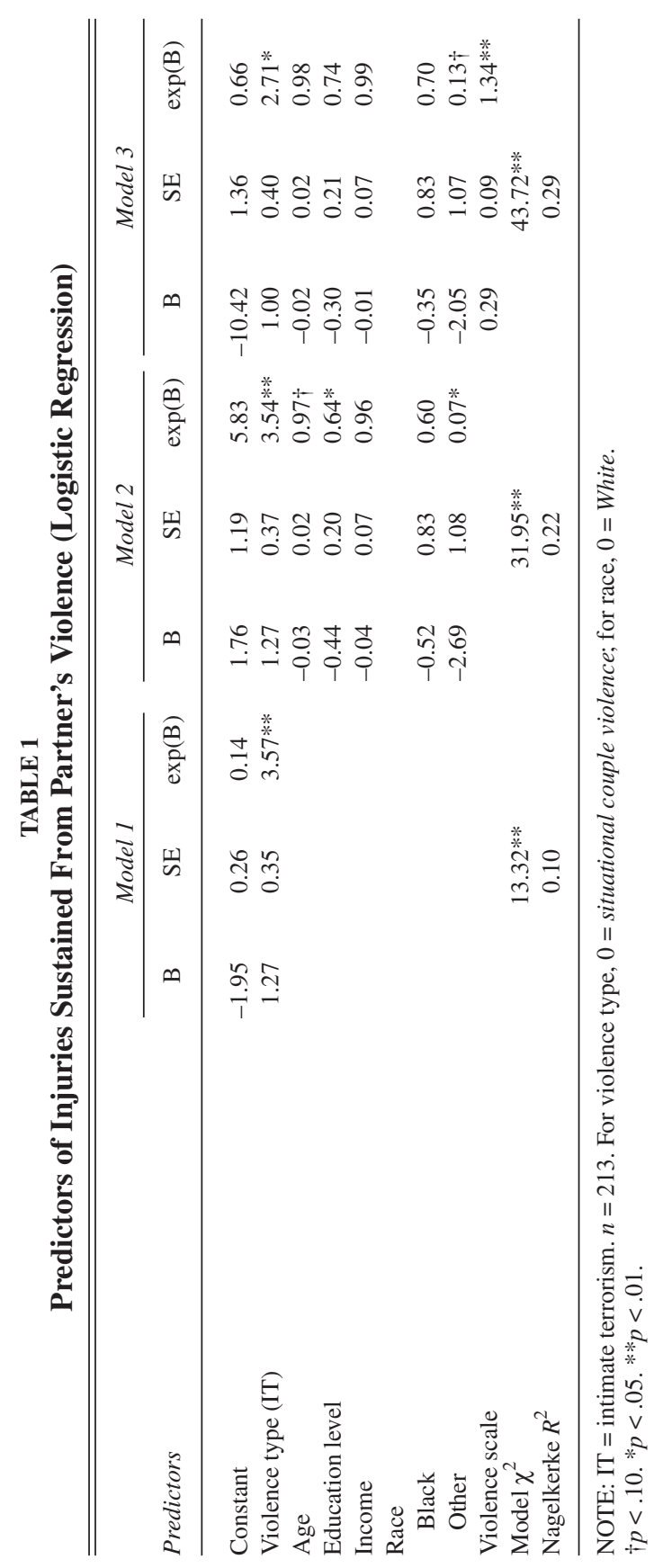




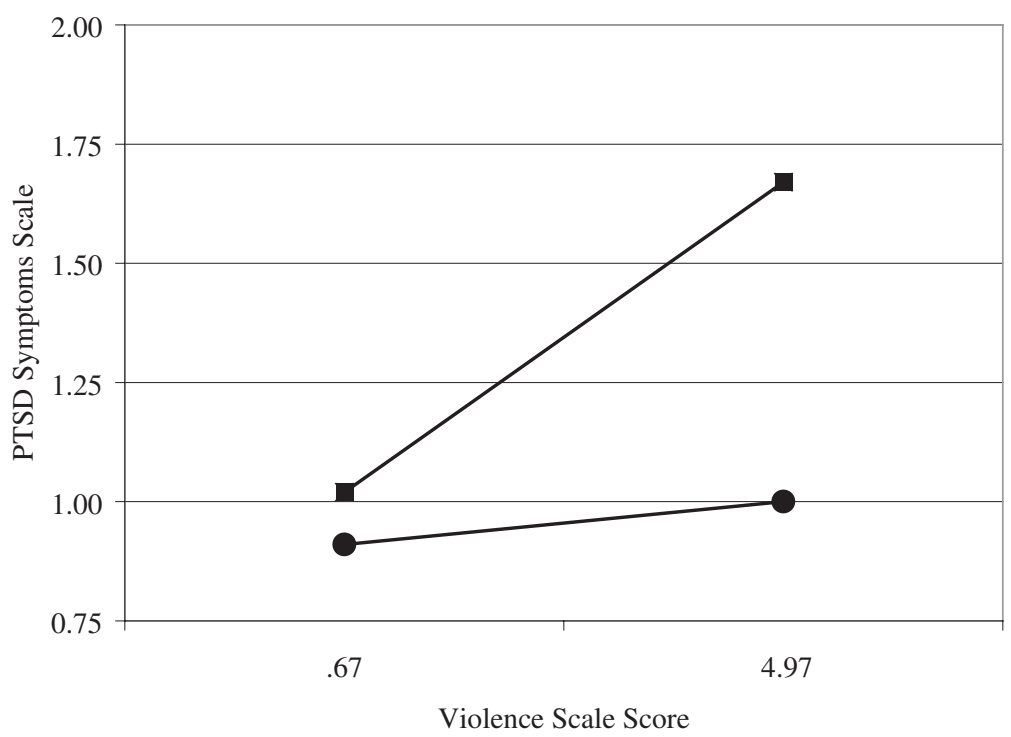

Violence Scale Score

$\multimap$ Intimate Terrorism $\longrightarrow$ Situational Couple Violence

Figure 1: PTSD Symptoms by Type and Level of Violence NOTE: PTSD = post-traumatic stress disorder.

Scale, as were age, education level, and income (Model 3). The interaction between violence type and Violence Scale score was not statistically significant $(t=1.35, p=.18)$, indicating that experiencing any type of violence and higher scores on the Violence Scale independently increased depression symptoms.

The final analyses concerning respondent well-being examined drug use, specifically respondents' use of painkillers, tranquilizers, and antidepressants in the month prior to the interview. Three separate hierarchical logistic regression analyses were conducted. First, results indicated that victims of intimate terrorism were more likely than women in nonviolent relationships to use painkillers, even after considering demographic information and scores on the Violence Scale (see Table 4). Experiencing situational couple violence did not increase the likelihood of using pain- 


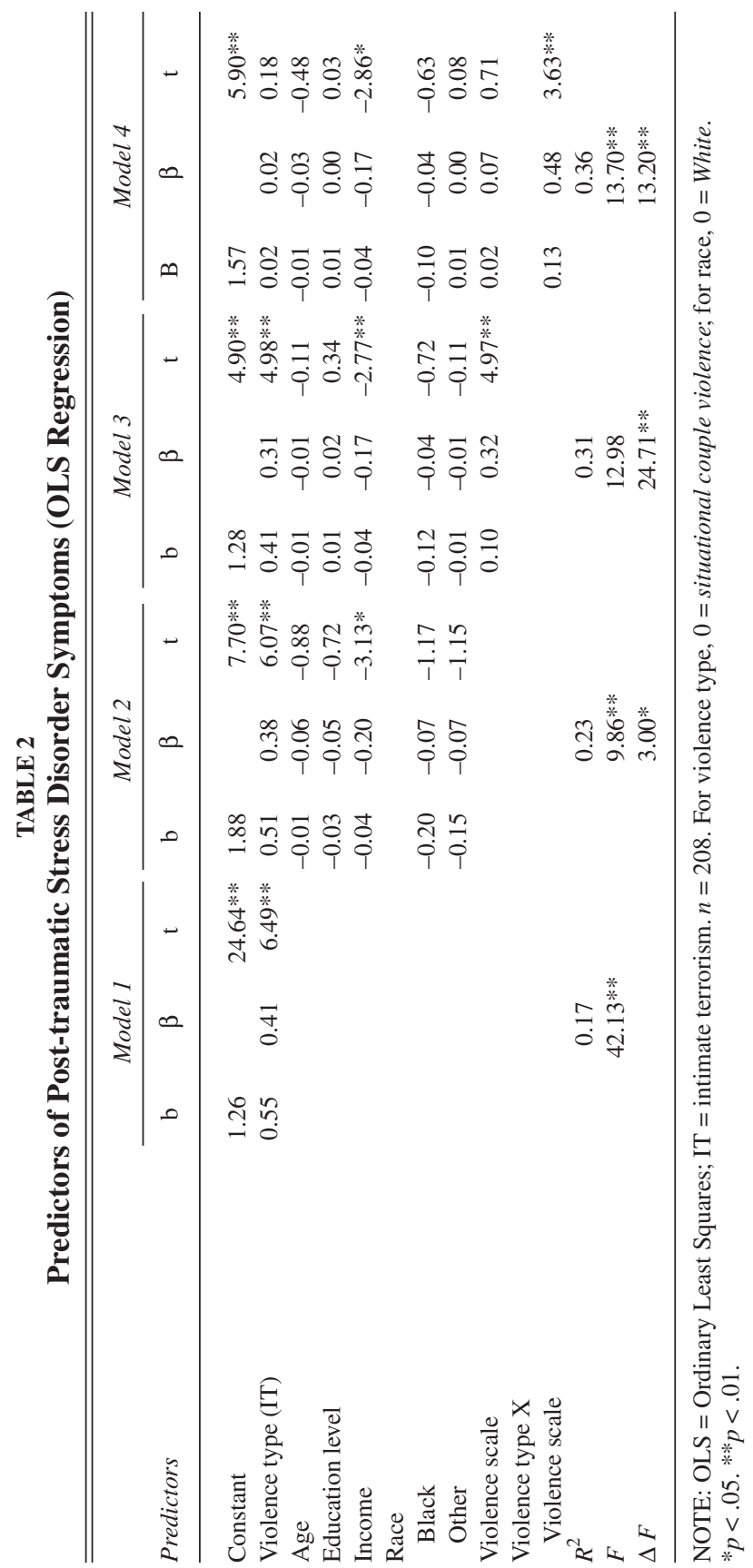




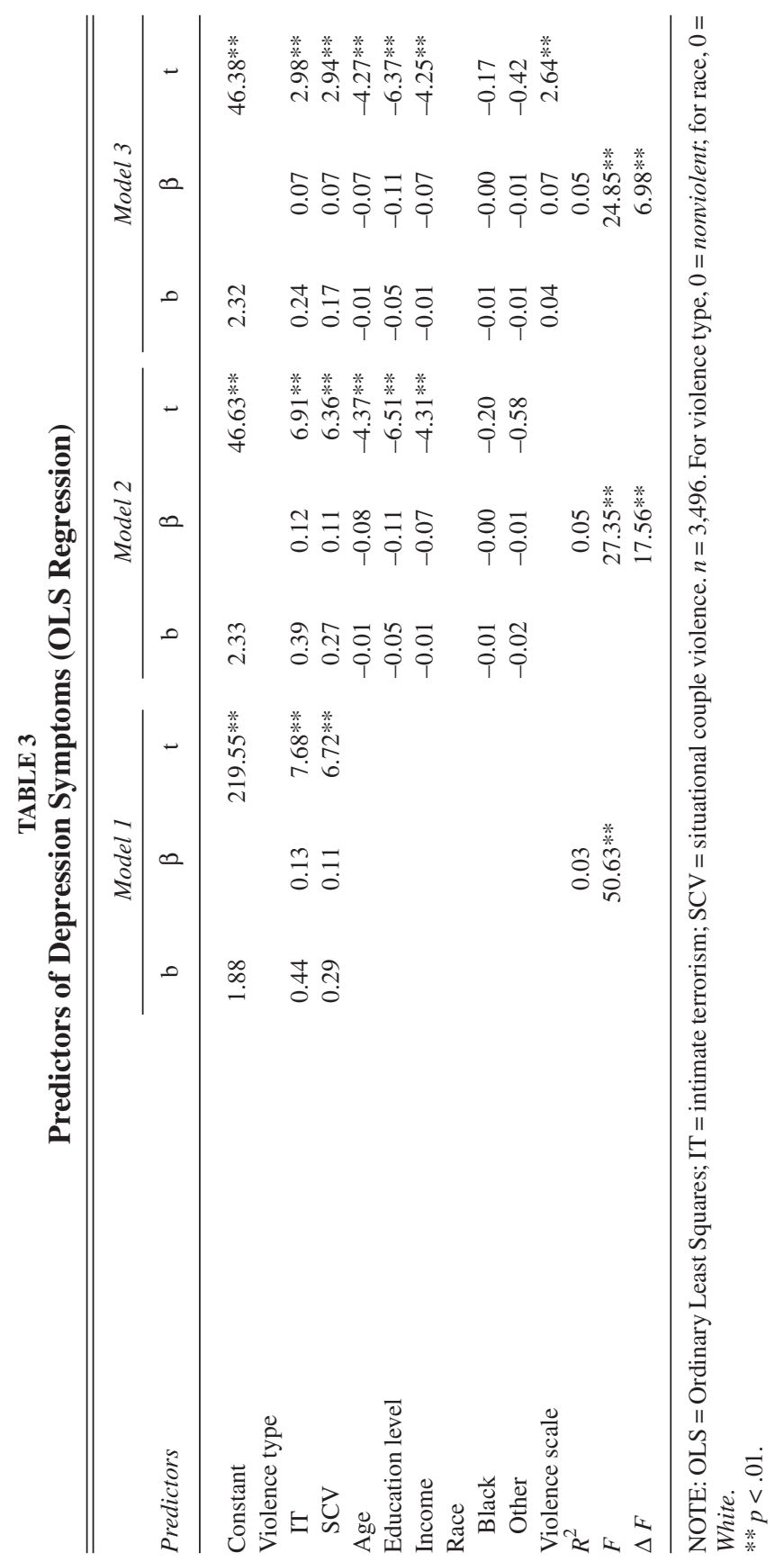




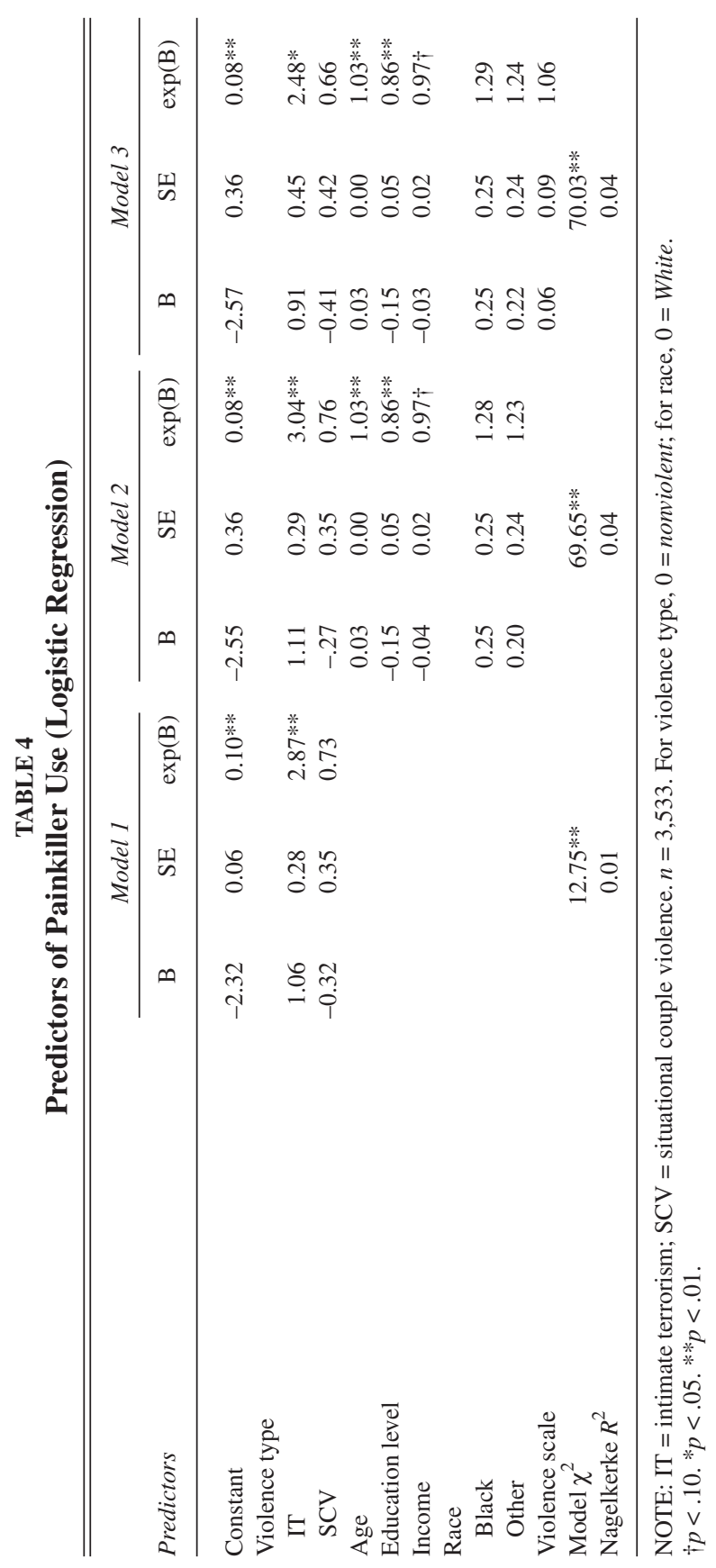


killers. Furthermore, additional post hoc analyses revealed that compared to victims of situational couple violence, victims of intimate terrorism were clearly more likely to use painkillers $(\exp (B)=3.73, p<.01)$.

Second, results revealed that the odds that victims of intimate terrorism would use tranquilizers were more than three times those of women who did not experience violence, whereas victims of situational couple violence were not at an increased risk (see Table 5). These results held even after considering demographic information and scores on the Violence Scale. Follow-up analyses, however, revealed that the difference in likelihood between victims of intimate terrorism and victims of situational couple violence was not statistically different $(\exp (B)=1.65, p=.31)$. Moreover, scores on the Violence Scale were not related to tranquilizer use.

Finally, regarding antidepressant use, results indicated that both victims of intimate terrorism and victims of situational couple violence were more likely than women in nonviolent relationships to use antidepressants, even after considering demographic information and scores on the Violence Scale (see Table 6). Similar to the results concerning tranquilizer use, the likelihood of using antidepressants was not significantly different for victims of intimate terrorism and victims of situational couple violence $(\exp (B)=1.05, p=.93)$.

Hypothesis 4: Intimate terrorism interferes more with daily activities than situational couple violence does.

Once again, we are faced with a very conservative test of our hypothesis, as questions about missed work were asked only with regard to the impact of the most recent incident of violence. Nonetheless, a hierarchical logistic regression revealed that after considering demographic information, victims of intimate terrorism were much more likely than victims of situational couple violence to have missed work as result of violence (see Table 7). The effect of violence type became considerably weaker and was no longer statistically significant when scores on the Violence Scale were considered, suggesting that level of violence may mediate the impact of intimate terrorism on missing work. The interaction between type of violence and scores on the Violence Scale was not statistically significant $(\exp (B)=.81, p=.39)$.

Hypothesis 5: Victims of intimate terrorism are more likely to leave their husband and seek help. 


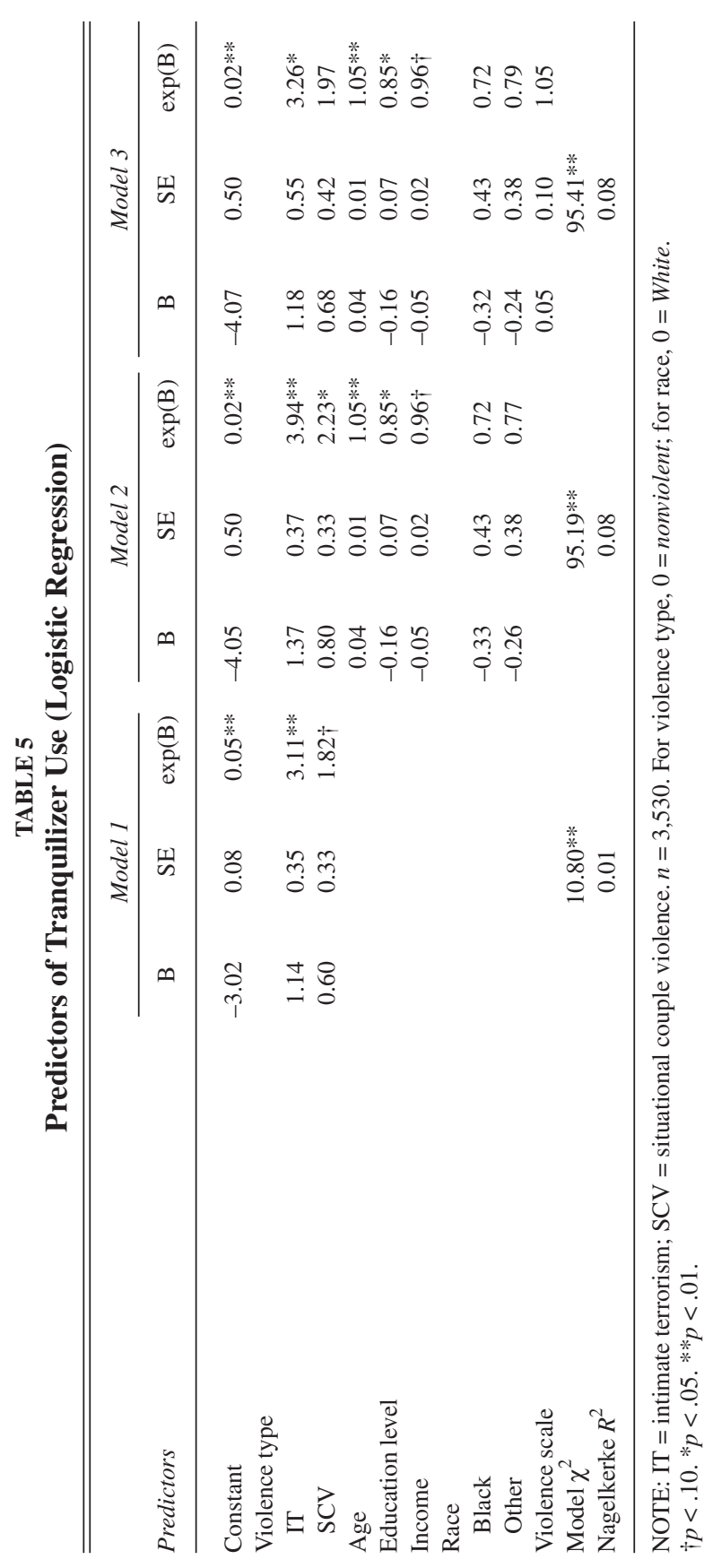




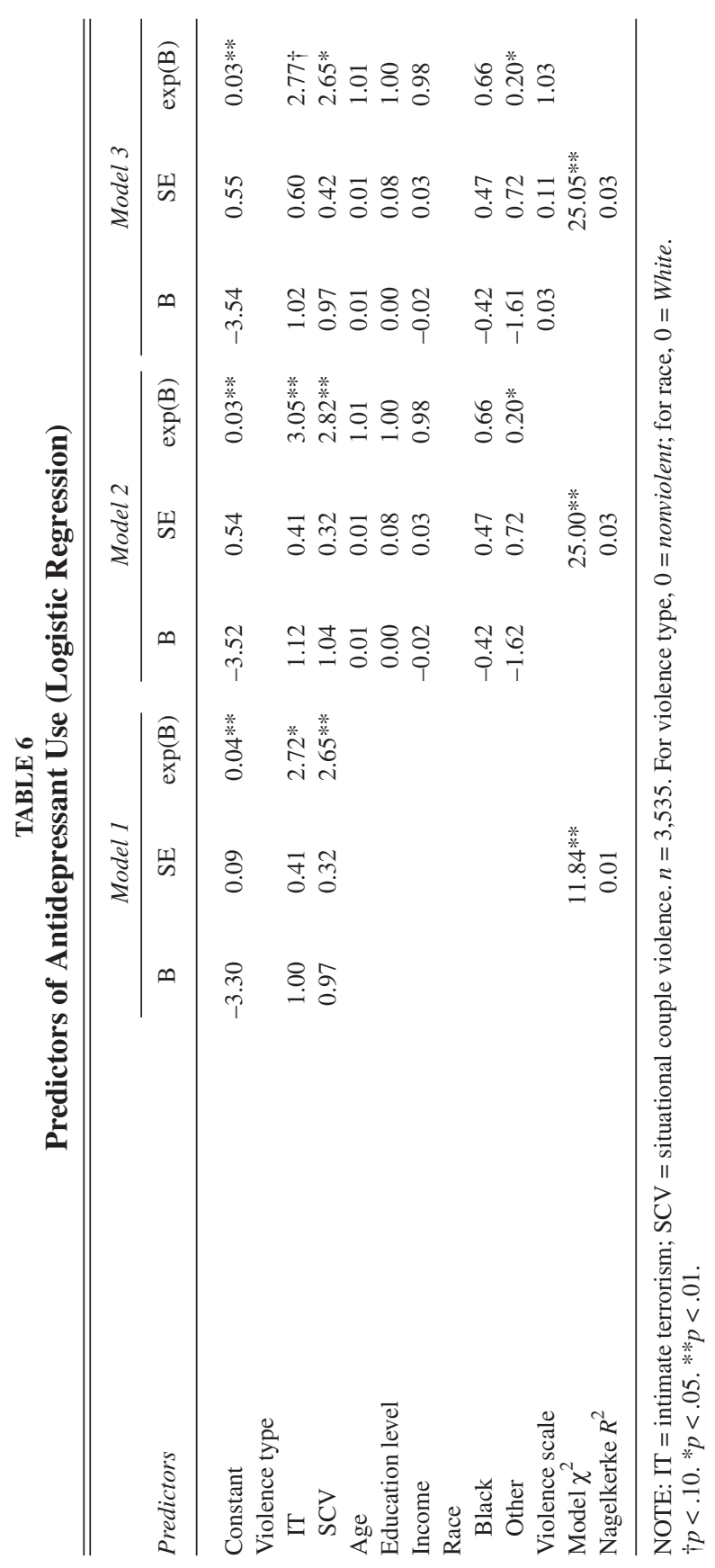




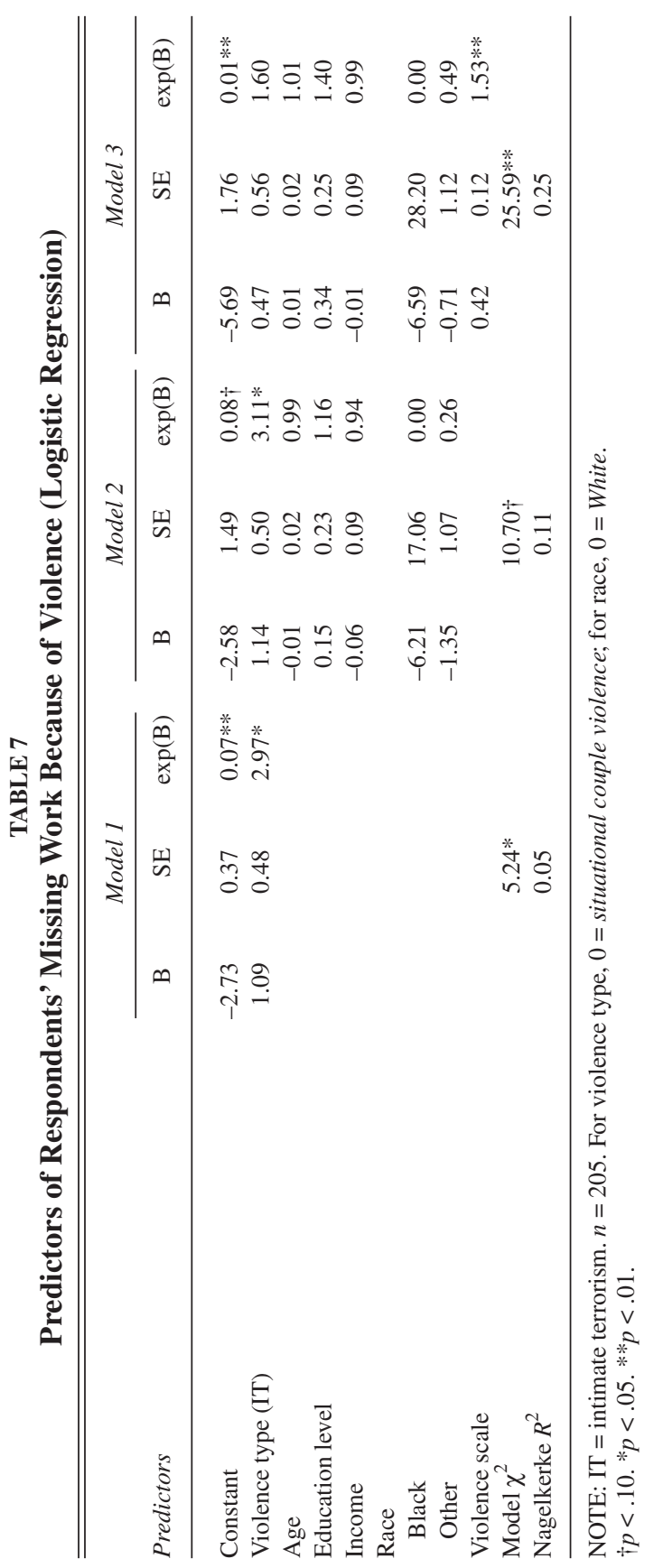


Results of a hierarchical OLS regression indicate that experiencing intimate terrorism was significantly related to the number of times the woman left the violent partner (see Table 8).

Although the effect of experiencing intimate terrorism decreased when Violence Scale scores were considered, it remained marginally significant. The interaction between intimate terrorism and the Violence Scale was not statistically significant $(t=1.59, p=.11)$.

Finally, we can ask where women who leave violent relationships seek help but, once again, only for the most recent time she left. Table 9 shows that although friends and relatives are the most common destinations for both types of victims, victims of intimate terrorism are more likely to acquire their own residence (suggesting a consideration of permanent separation) or to go to locations that are safe, either because of security (safe houses) or perhaps secrecy (hotels). Overall, these data provide reasonable support for Hypothesis 5.

\section{CONCLUSION}

The general pattern of the data presented above is clear. The consequences for women who experience intimate terrorism are different from those for women who experience situational couple violence. Women subjected to intimate terrorism are attacked more frequently and experience violence that is less likely to stop. They are more likely to be injured, to exhibit more of the symptoms of posttraumatic stress syndrome, to use painkillers (perhaps also tranquilizers and antidepressants), and to miss work. Furthermore, they are more likely to leave their husbands, leave them more often, and, when they leave, to seek their own residence or escape to locations that ensure safety.

These findings are not surprising once the distinction between violence embedded in general control over one's partner (intimate terrorism) and violence that erupts in response to more specific forms of conflict (situational couple violence) is made and understood. The partner violence literature, however, consists primarily of studies that make no such distinctions. When a sample (often from survey research) includes primarily situational couple violence mixed with substantially fewer cases of intimate terrorism, the consequences of the violence may not appear to be particularly dramatic. One might be puzzled, for example, by how few women report leaving their batterers. This finding, however, reflects a general problem with this type of sample; there may actually be very few batterers among the violent men. 


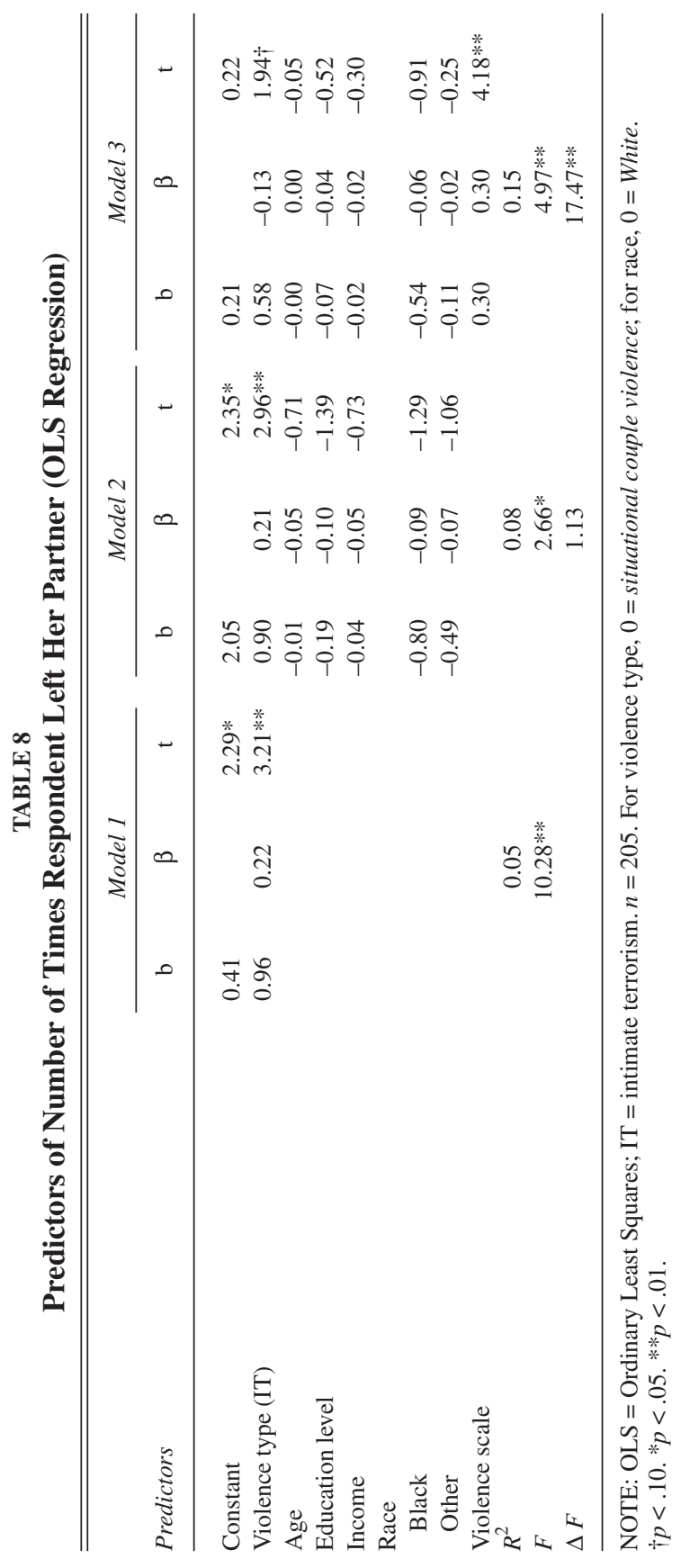


TABLE 9

Where Respondent Stayed by Violence Type

\begin{tabular}{|c|c|c|c|c|}
\hline \multirow[b]{3}{*}{ Where Respondent Stayed } & \multicolumn{4}{|c|}{ Violence Type } \\
\hline & \multicolumn{2}{|c|}{$\begin{array}{l}\text { Intimate } \\
\text { Terrorism }\end{array}$} & \multicolumn{2}{|c|}{$\begin{array}{c}\text { Situational } \\
\text { Couple Violence }\end{array}$} \\
\hline & $\%$ & $\mathrm{n}$ & $\%$ & $\mathrm{n}$ \\
\hline Relative's house & 40 & 12 & 70 & 21 \\
\hline With a friend & 10 & 3 & 23 & 7 \\
\hline Safe house, hotel or motel, got own place & 37 & 11 & 3 & 1 \\
\hline He left and she stayed, homeless shelter, other & 13 & 4 & 3 & 1 \\
\hline
\end{tabular}

$\chi^{2}=17.06 . d f=3 . p<.01$.

Even in the current analysis, in which our criterion for defining intimate terrorism is a relatively low level of control, for victims of intimate terrorism, the odds of being injured are double those for victims of situational couple violence. Likewise, they score higher on a measure of posttraumatic stress symptomology and leave their husbands more often. To grasp the nature of abuse from survey data rather than from shelters, hospitals, and the courts, it is crucial that we make these distinctions among types of violence. This simple yet significant step will keep us from making generalizations about abuse from data consisting of partner violence that may not meet commonly accepted definitions of abuse.

Just as intimate terrorism and situational couple violence have different outcomes, they probably have different causes and remedies. Only research that attends to these differences can effectively inform social policy, educational efforts, and intervention strategies. For example, because women subjected to intimate terrorism are more likely to suffer psychologically, sustain injuries, and miss work, they are at an increased risk of being unable to achieve and maintain self-sufficiency (Leone, Johnson, Cohan, \& Lloyd, 2004). Thus, social policies that temporarily or permanently restrict a woman's income (such as time limits on receipt of temporary aid to needy families) may be especially detrimental to women entrapped in intimate terrorism because they are already at risk for being unable to secure self-sufficiency. These are the very women who are most likely trying to escape from their partner, and social policy needs to contribute to their self-sufficiency, not undermine it. 
In the realm of prevention, educational programs commonly treat partner violence as a unitary phenomenon, referring to it as abuse or battering. In these situations, prevalence statistics that describe abuse are often drawn from survey data that include large numbers of incidents of situational couple violence. The numbers, therefore, greatly exaggerate the prevalence of abuse. Speakers who claim that $50 \%$ of American wives experience battering at some point in their marriage undermine their own credibility. We need to provide statistics that are appropriately focused on intimate terrorism. Educational programs that distinguish between types of violence will be better able to present information in the appropriate context, without misrepresenting the nature or prevalence of either intimate terrorism or situational couple violence.

In the realm of direct intervention, programs that do not make distinctions may inadvertently do a disservice to some women. For example, in initial client contacts, shelter personnel typically focus on the pattern of power and control involved in intimate terrorism. Women who have experienced situational couple violence that does not fit this pattern may then be less likely to identify their relationship as problematic and may therefore choose not to access services that might have been helpful to them. Screening instruments that adequately distinguish between types of violence can help practitioners to identify the underlying nature of the problem and to recommend appropriate interventions. For example, it is common for couples involved in violence to be referred to couples counseling or mediation, a strategy that can be extremely dangerous for women entrapped in intimate terrorism, who risk retaliation if they disclose information about the abuse in front of the abuser. In this situation, couples counseling would be not only inappropriate but dangerous. For couples involved in situational couple violence, however, such counseling might provide useful skills in problem solving, anger management, and conflict resolution.

In general, the current study demonstrates that research on partner violence can be more effective by distinguishing between types of violence. We have shown that situational couple violence and intimate terrorism can be identified and analyzed separately in survey data and that they have different effects on their victims. M. P. Johnson (1999) has shown that both types also can be found in data gathered from agency populations. Thus, it is crucial that researchers make these distinctions in their research and adequately define the nature of the violence they study. We have demonstrated that intimate terrorism and situational couple violence are not the same phenomenon. Scientific research that fails to make this distinction 
risks making inaccurate and potentially dangerous overgeneralizations about partner violence.

\section{REFERENCES}

Bradbury, T., Rogge, R., \& Lawrence, E. (2001). Reconsidering the role of conflict in marriage. In A. Booth, A. C. Crouter, \& M. Clements (Eds.), Couples in conflict (pp. 59-81). Mahwah, NJ: Lawrence Erlbaum.

Brandwein, R. A. (1998). Battered women, children, and welfare reform: The ties that bind. Thousand Oaks, CA: Sage.

Browne, A., Salomon, A., \& Bassuk, S. S. (1999). The impact of recent partner violence on poor women's capacity to maintain work. Violence Against Women, 5, 393-426.

Campbell, J. C., Rose, L., Kub, J., \& Nedd, D. (1998). Voices of strength and resistance: A contextual and longitudinal analysis of women's responses to battering. Journal of Interpersonal Violence, 13, 743-762.

Dobash, R. E., \& Dobash, R. P. (1979). Violence against wives: A case against patriarchy. New York: Free Press.

Ferraro, K. J. (1997). Battered women: Strategies for survival. In A. Carderelli (Ed.), Violence among intimate partners: Patterns, causes and effects (pp. 124-140). New York: Macmillan.

Frieze, I. H., \& Browne, A. (1989). Violence in marriage. In L. Ohlin \& M. Tonry (Eds.), Family violence (pp. 163-218). Chicago: University of Chicago Press.

Gelles, R. J., \& Straus, M. A. (1988). Intimate violence: The causes and consequences of abuse in the American family. New York: Simon \& Schuster.

Giles-Sims, J. (1998). The aftermath of partner violence. In J. L. Jasinski \& L. M. Williams (Eds.), Partner violence: A comprehensive review of 20 years of research (pp. 44-72). Thousand Oaks, CA: Sage.

Holtzworth-Munroe, A., Smutzler, N., \& Sandin, E. (1997). A brief review of the research on husband violence: Part II: The psychological effects of husband violence on battered women and their children. Aggression and Violent Behavior, 2, 179-213.

Johnson, H. (1996). Dangerous domains: Violence against women in Canada. Toronto: Nelson Canada.

Johnson, M. P. (1995). Patriarchal terrorism and common couple violence: Two forms of violence against women. Journal of Marriage and the Family, 57, 283-294.

Johnson, M. P. (1999, November). Two types of violence against women in the American family: Identifying patriarchal terrorism and common couple violence. Paper presented at the National Council on Family Relations annual meetings, Irvine, CA.

Johnson, M. P. (2001). Conflict and control: Symmetry and asymmetry in domestic violence. In A. Booth, A. C. Crouter, \& M. Clements (Eds.), Couples in conflict (pp. 95-104). Mahwah, NJ: Lawrence Erlbaum.

Johnson, M. P., \& Ferraro, K. J. (2000). Research on domestic violence in the 1990s: Making distinctions. Journal of Marriage and the Family, 62, 948-963.

Kirkwood, C. (1993). Leaving abusive partners: From the scars of survival to the wisdom for change. Newbury Park, CA: Sage.

Leone, J. M., Johnson, M. P., Cohan, C. M., \& Lloyd, S. (2004). Consequences of male partner violence for low-income minority women. Journal of Marriage and Family, 66, 471489. 
Lloyd, S. (1997). The effects of domestic violence on women's employment. Law \& Policy, 19, 139-167.

Lloyd, S. A., \& Emery, B. C. (2000). The dark side of courtship: Physical and sexual aggression. Thousand Oaks, CA: Sage.

Macmillan, R., \& Gartner, R. (1999). When she brings home the bacon: Labor-force participation and the risk of spousal violence against women. Journal of Marriage and the Family, 61, 947-958.

Pence, E., \& Paymar, M. (1993). Education groups for men who batter: The Duluth Model. New York: Springer.

Stark, E., \& Flitcraft, A. (1996). Women at risk: Domestic violence and women's health. Thousand Oaks, CA: Sage.

Steinmetz, S. K. (1986). The violent family. In M. Lystad (Ed.), Violence in the home: Interdisciplinary perspectives (pp. 51-67). New York: Brunner/Mazel.

Stets, J. E. (1988). Domestic violence and control. New York: Springer

Stets, J. E., \& Straus, M. A. (1989). The marriage license as a hitting license: A comparison of assaults in dating, cohabiting, and married couples. Journal of Family Violence, 4, 161180.

Straus, M. A. (1990a). The Conflict Tactics Scales and its critics: An evaluation and new data on validity and reliability. In M. A. Straus \& R. J. Gelles (Eds.), Physical violence in American families: risk factors and adaptations to violence in 8, 145 families (pp. 49-73). New Brunswick, NJ: Transaction Press.

Straus, M. A. (1990b). Measuring intrafamily conflict and violence: The Conflict Tactics (CT) Scales. In M. A. Straus \& R. J. Gelles (Eds.), Physical violence in American families: Risk factors and adaptations to violence in 8,145 families (pp. 29-47). Brunswick, NJ: Transaction Press.

Straus, M. A. (1999). The controversy over domestic violence by women: A methodological, theoretical, and sociology of science analysis. In X. B. Arriaga \& S. Oskamp (Eds.), Violence in intimate relationships (pp. 17-44). Thousand Oaks, CA: Sage.

Straus, M. A., \& Gelles, R. J. (Eds.). (1990). Physical violence in American families: Risk factors and adaptations to violence in 8,145 families. New Brunswick, NJ: Transaction Press.

Straus, M. A., Gelles, R. J., \& Steinmetz, S. K. (1980). Behind closed doors: Violence in the American family. Garden City, NY: Doubleday.

Straus, M. A., \& Smith, C. (1990). Family patterns and primary prevention of family violence. In M. A. Straus \& R. J. Gelles (Eds.), Physical violence in American families: Risk factors and adaptations to violence in 8,145 families (pp. 507-526). Brunswick, NJ: Transaction Press.

Tjaden, P., \& Thoennes, N. (1999). Extent, nature, and consequences of intimate partner violence: Findings from the National Violence Against Women Survey. Washington, DC: National Institute of Justice / Centers for Disease Control and Prevention.

Tolman, R. M. (1989). The development of a measure of psychological maltreatment of women by their male partners. Violence and Victims, 4, 159-177.

Weiss, D. S., \& Marmar, C. R. (1997). The Impact of Event Scale—revised. In J. P. Wilson \& T. M. Keane (Eds.), Assessing psychological trauma and PTSD (pp. 399-411). New York: Guilford.

Yllo, K., \& Bograd, M. (Eds.). (1988). Feminist perspectives on wife abuse. Newbury Park, CA: Sage. 